Hydrol. Earth Syst. Sci., 17, 2529-2542, 2013

www.hydrol-earth-syst-sci.net/17/2529/2013/

doi:10.5194/hess-17-2529-2013

(C) Author(s) 2013. CC Attribution 3.0 License.

\title{
Variation in turbidity with precipitation and flow in a regulated river system - river Göta Älv, SW Sweden
}

\author{
G. Göransson ${ }^{1,2}$, M. Larson ${ }^{2}$, and D. Bendz ${ }^{1}$ \\ ${ }^{1}$ Swedish Geotechnical Institute, 58193 Linköping, Sweden \\ ${ }^{2}$ Water Resources Engineering, Lund University, 22100 Lund, Sweden \\ Correspondence to: G. Göransson (gunnel.goransson@swegeo.se)
}

Received: 3 December 2012 - Published in Hydrol. Earth Syst. Sci. Discuss.: 10 January 2013

Revised: 27 May 2013 - Accepted: 3 June 2013 - Published: 8 July 2013

\begin{abstract}
The turbidity variation in time and space is investigated in the downstream stretch of the river Göta Älv in Sweden. The river is heavily regulated and carries the discharge from the largest fresh water lake in Sweden, Lake Vänern, to the outflow point in Göteborg Harbour on the Swedish west coast. The river is an important waterway and serves as a fresh-water supply for 700000 users. Turbidity is utilised as a water quality indicator to ensure sufficient quality of the intake water to the treatment plant. The overall objective of the study was to investigate the influence of rainfall, surface runoff, and river water flow on the temporal and spatial variability of the turbidity in the regulated river system by employing statistical analysis of an extensive data set. A six year long time series of daily mean values on precipitation, discharge, and turbidity from six stations along the river were examined primarily through linear correlation and regression analysis, combined with nonparametric tests and analysis of variance. The analyses were performed on annual, monthly, and daily bases, establishing temporal patterns and dependences, including; seasonal changes, impacts from extreme events, influences from tributaries, and the spatial variation along the river. The results showed that there is no simple relationship between discharge, precipitation, and turbidity, mainly due to the complexity of the runoff process, the regulation of the river, and the effects of Lake Vänern and its large catchment area. For the river Göta Älv, significant, positive correlations between turbidity, discharge, and precipitation could only be found during periods with high flow combined with heavy rainfall. Local precipitation does not seem to have any significant impact on the discharge in the main river, which is primarily governed by precipitation at catchment scale. The discharge from Lake Vänern determines the
\end{abstract}

base level for the turbidity in the river, whereas local surface runoff and tributary discharge induced by rainfall govern the temporal variability in turbidity. Autocorrelation analysis indicates a temporal persistence in turbidity of about 10 days. The results also show that erosion along the main river, from the river bed and banks, is not a dominant contributor to the suspended sediment transport in the river under normal conditions. Further studies on the correlation between turbidity and suspended sediment transport and its relation to erosion processes are suggested.

\section{Introduction}

\subsection{Background}

Suspended sediment, a major contributor to turbidity, is a potential contaminant carrier (Håkanson, 2006; Lick, 2009; Schoellhamer et al., 2007; Zonta et al., 2005), as well as being connected to bacterial impact and light suppression with effects on BOD, DO, and pH (Bhutiani and Khanna, 2007; Gauthier et al., 2003; Håkanson, 2006; Lawler et al., 2006).

Several studies have demonstrated a strong relationship between discharge and suspended sediment concentration, with different time lags depending on the characteristics of the river/catchment system (Alexandrov et al., 2007; Antonelli et al., 2008; Lawler et al., 2006; Townsend-Small et al., 2008; Vericat and Batalla, 2005; Zabaleta et al., 2007; Zonta et al., 2005). Numerous regression relationships (i.e., sediment rating curves) have therefore been developed in order to predict suspended sediment concentration during flood events (Iadanza and Napolitano, 2006; Picouet et al., 
2001; Schmidt and Morche, 2006; Townsend-Small et al., 2008; Vericat and Batalla, 2005; Wang et al., 2008; Yang et al., 2007). Nevertheless, the relationship between discharge and suspended sediment concentration is not straightforward (Hodgkins, 1999) since it is influenced by the sediment supply from the catchment, the intensity and spatial distribution of precipitation, human activities (i.e. deforestation, agricultural reclamation, urbanisation, reinforcement of river banks), as well as the erosive power of the river (Wang et al., 2008).

The close relationship between suspended sediment concentration and turbidity has resulted in turbidity often being used as a surrogate for the concentration of suspended sediment (Chanson et al., 2008; Hamilton et al., 1998; Kineke and Sternberg, 1992; Ochiai and Kashiwaya, 2010; Pavanelli and Bigi, 2005a,b; Thomas and Lewis, 1995; Williamson and Crawford, 2011). Turbidity is therefore a key parameter when monitoring surface water quality because of its relation to suspended sediment concentration but also because of its effect on the eco-environment. In contrast to direct sampling for analysis of sediment concentration, a turbidity monitor employs optical techniques based on the scattering of light and provides the possibility for continuous, spatial and temporal measurements in a cost-effective manner (Gao et al., 2008; Kineke and Sternberg, 1992; Pavanelli and Bigi, 2005b; Pavanelli and Pagliarani, 2002). Measures of turbidity include suspended particles and colloids, dead and living organisms, and inorganic and organic particles (Bhutiani and Khanna, 2007; Håkanson, 2006). However, the optical technique makes the monitor sensitive not only to the sediment content in the water, but also to climatological and biological factors (Gao et al., 2008; Hawley, 2004; Håkanson, 2006; Wass et al., 1997). Recorded turbidity levels are affected by particle size, aggregation, air bubbles, runoff characteristics, waste water discharge properties, weeds and their break down products, humic acids and other organic compounds from decay of organic matters, and high iron concentration. Thus, calibration is typically necessary for relating sediment concentration to turbidity (Hamilton et al., 1998; Pfannkuche and Schmidt, 2003; Wass et al., 1997; Williamson and Crawford, 2011).

Previous studies have shown correlation between turbidity and precipitation (Hamilton and Luffman, 2009; Lopez-Tarazon et al., 2009) and turbidity and discharge (Hamilton and Luffman, 2009). Periods with high turbidity are normally associated with the wet season when surface runoff transports sediments from the soil to the river and when the water flow is generally higher and more turbulent, which does not allow for the settlement of particles on the river bed (Bhutiani and Khanna, 2007; Maillard and Pinheiro Santos, 2008). Other studies have demonstrated relationships between turbidity and microorganisms, such as faecal coliforms (Hamilton et al., 1998; Huey and Meyer, 2010; Maillard and Pinheiro Santos, 2008; Åström et al., 2007) and plankton (Néstor et al., 2001), as well as between turbidity and nitrogen (Maillard and Pinheiro Santos, 2008). There are indications that turbidity is positively correlated with temperature during spring/summer (Vernile et al., 2009), because of algal growth, and negatively correlated during fall/winter due to the decay of plants, leaves etc. A negative correlation has been found between turbidity and conductivity (Winston and Criss, 2002).

\subsection{Objectives and procedure}

The overall objective of this study is to improve the understanding of the variability of turbidity (measured as Formazin Nephelometric Units, abbreviated as FNU) in a regulated river. Specifically, significant dependencies were sought between turbidity and rainfall, surface runoff, and river flow. A high-quality data set, encompassing detailed turbidity measurements in time at six stations along the river Göta Älv in Sweden, was analysed.

Statistical analyses were performed based on a selected number of hypotheses regarding the main processes governing the turbidity in the river. First, the turbidity data were examined at different temporal scales, including daily, eventbased, seasonal, and annual scale. Then spatial variations in turbidity were explored together with the relationships between measurement stations along the river. Finally, a factorial and main effect analysis of variance was carried out to investigate the contribution from different processes to the recorded turbidity.

\section{Site description}

\subsection{Göta Älv study area}

The focus of this study is on the lower part of the river Göta Älv and its catchment. The study area includes the stretch of river from Lake Vänern to the outlet at the city of Göteborg (see Fig. 1), comprising a length of $93 \mathrm{~km}$ with a catchment area of about $3500 \mathrm{~km}^{2}$. The study area constitutes a small part of the entire Göta Älv river basin, which also includes the Lake Vänern catchment. This catchment area encompasses about $50000 \mathrm{~km}^{2}$, making it the largest in Sweden (Kvarnäs, 2001). Lake Vänern is also the largest lake in Sweden with a volume of about $153 \mathrm{~km}^{3}$. It contributes to more than $90 \%$ of the flow in the studied river section, and the rest originates from local tributaries, direct runoff, and groundwater. The discharge from Lake Vänern to the Göta $\ddot{A} l v$ is regulated to a maximum discharge of $1030 \mathrm{~m}^{3} \mathrm{~s}^{-1}$ in order to prevent downstream bank erosion and flooding, thus limiting the discharge capacity from the lake. At least 25 tributaries have their outflows to the river south of Lake Vänern, of which Slumpån (mean flow $3.4 \mathrm{~m}^{3} \mathrm{~s}^{-1}$ ), Gårdaån (mean flow $1 \mathrm{~m}^{3} \mathrm{~s}^{-1}$ ) and Grönån (mean flow $4 \mathrm{~m}^{3} \mathrm{~s}^{-1}$ ) are the three largest (Fig. 1). South of the city of Kungälv, Göta Älv bifurcates around a large island; the northern branch (the river name changes to Nordre Älv) receives approximately $2 / 3$ of 


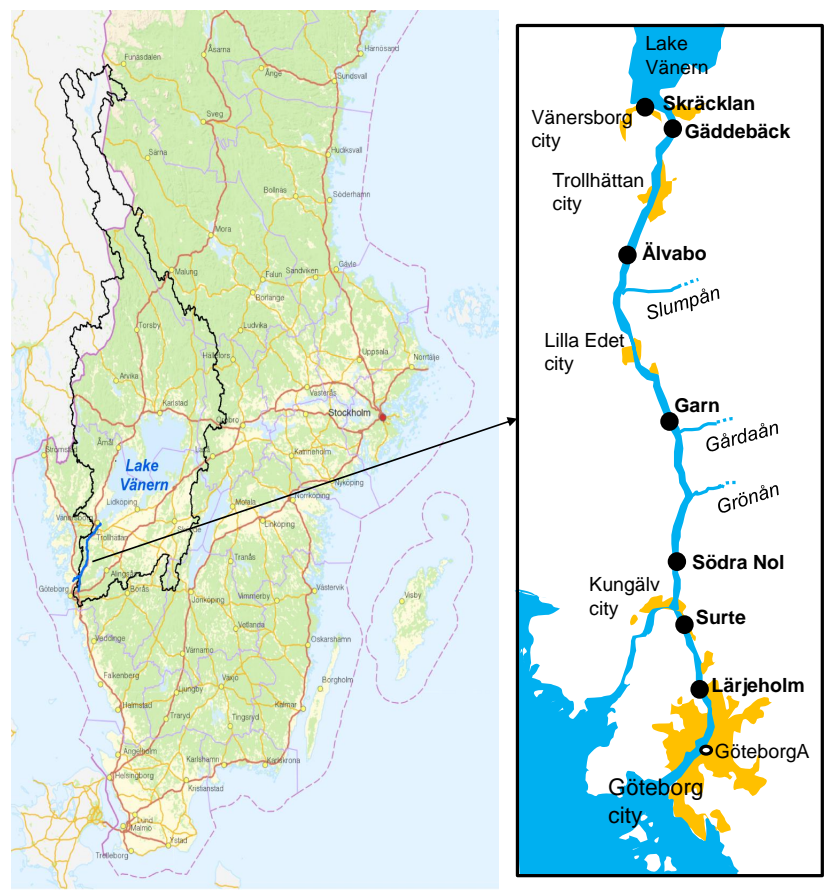

Fig. 1. The Göta Älv catchment (left panel) and its section from Lake Vänern to the Kattegatt sea, with seven stations for water quality monitoring and the outlets from three main tributaries shown (right panel). (Background map ${ }^{\circledR}$ Lantmäteriet, data from Swedish Meteorological and Hydrological Institute.)

the total discharge, whereas the remaining $1 / 3$ takes the route through the southern branch (still referred to as the Göta Älv). The mean annual discharge into the sea (both branches) is $565 \mathrm{~m}^{3} \mathrm{~s}^{-1}$. The travel time from the lake to the farthest gauging station (Lärjeholm) varies between 1.5-5 days depending on the discharge. The change in elevation from the Kattegatt sea to the lake is $44 \mathrm{~m}$, regulated at locks to facilitate navigation. The river is regulated by three hydropower stations located at Vargön (Vänersborg, near gauging station Gäddebäck), Trollhättan, and Lilla Edet (see Fig. 1). In addition, there is a flow shield in the Nordre Älv to protect the river from salt-water intrusion. The water level in Lake Vänern, together with the fluctuating energy demand, governs the variation in river discharge.

The river sediments consist mainly of thick layers of firm cohesive glacial and postglacial sediments with thin layers of silt and sand. The river morphology is influenced by occasional landslides. The mean width of the river is about 100$200 \mathrm{~m}$ but it widens to $300 \mathrm{~m}$ just before the bifurcation, after which it again narrows down to about $100-200 \mathrm{~m}$. The thalweg has a depth of 7-10 $\mathrm{m}$ with deeper local cavities. The areas surrounding the river are pasture land, forests, bed rock, and small urban areas. Almost no sedimentation occurs in the river, and the transport of inorganic suspended particles has been estimated to $180000 \mathrm{t} \mathrm{yr}^{-1}$, of which $70000 \mathrm{t} \mathrm{yr}^{-1}$ are transported through the southern branch. Figure 2 illustrates

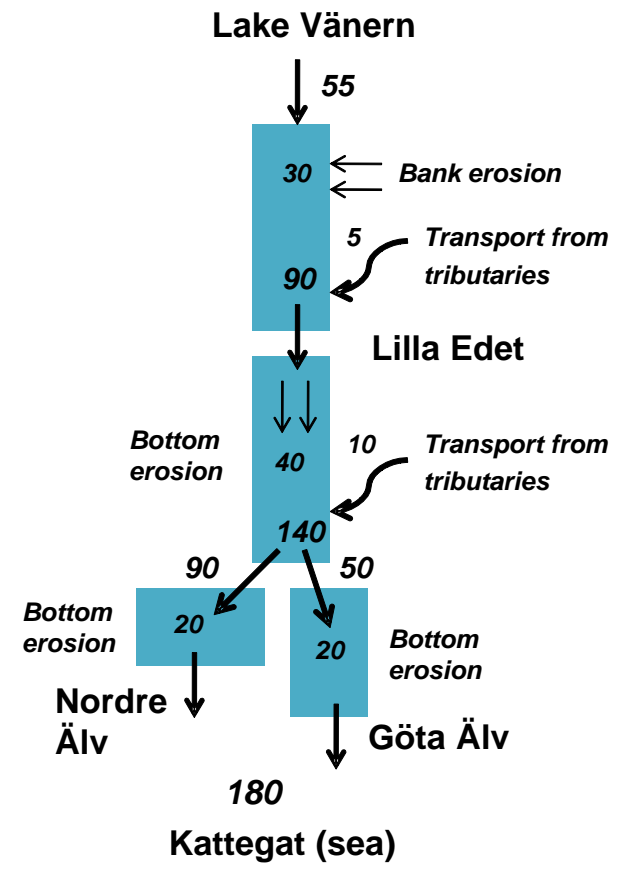

Fig. 2. Net sediment budget for the river Göta Älv downstream from Lake Vänern (Rydell et al., 2011).

a net sediment budget for the studied river section downstream from Lake Vänern, compiled mainly from an older study from 1963 (Rydell et al., 2011; Sundborg and Norrman, 1963). In the study from 1963, the river was divided into four different reaches in accordance with the general morphology and the prevailing transport processes. For the section between Vänern and Lilla Edet municipality, bank erosion was assumed to dominate the erosion processes in the river, whereas the reaches south of Lilla Edet primarily would exhibit bottom erosion, possibly with intermittent periods of sedimentation.

\subsection{River water usage}

The river Göta Älv is an important waterway, the recipient of treated wastewater, as well as the source of drinking water for 700000 users. The water quality in the river is primarily affected by direct runoff from urban, rural, and livestock areas, wastewater from urban areas, combined sewer overflow during heavy rainfall (Åström et al., 2007), leakage from contaminated sites, and accidental spills from industries and vessels (Göransson et al., 2009). In addition, the inflow from Lake Vänern and the discharge from the different tributaries into the river have impact on the water quality.

Turbidity (as well as pH, redox, and conductivity) is continuously recorded at seven gauging stations along the investigated river section with the purpose of providing an early warning in case of deteriorating water quality. The farthest downstream gauging station is located at the fresh water intake (Lärjeholm; see Fig. 1). A turbidity level of $12 \mathrm{FNU}$ 
is employed as a simple criterion to temporarily close the intake.

\section{Method}

\subsection{Data collection}

Turbidity data were obtained from the water supply plant at Lärjeholm, which belongs to Göteborg. This study also includes turbidity data from the gauging stations Skräcklan, Gäddebäck, Garn, Södra Nol, Surte and Lärjeholm (Fig. 1). Measurements at the gauging station Älvabo started only recently; thus, this station only has a short data record and it was excluded from the analysis. Turbidity values reported here were measured in FNU, which is the recommended Swedish standard. All turbidity monitors (Hach surf scatter 6) yield stable recordings with an accuracy of about $\pm 5 \%$. The turbidity is logged every second and recorded as minute-averaged values at the different stations. In this study daily averages were employed based on the minute-averaged values. The water intake to the optical turbidity monitors are located 1-2 $\mathrm{m}$ above the bottom, at 2-3 $\mathrm{m}$ water depth (except for Skräcklan that is located at $8-10 \mathrm{~m}$ depth in a bay of Lake Vänern). Measurements have shown that the vertical variation in turbidity is low since turbulence in the river flow provides good vertical mixing of the sediment. Turbidity is measured on the free-water surface, which is continuously pumped through a tube and flows over an open edge (turbidity is hence not measured through a cuvette or a similar apparatus). The sensors are cleaned once a week and it is therefore assumed that biofouling had negligible influence on the measurements. All turbidity data has been checked for anomalies. This is routinely done by experienced staff at the water supply plant each year and incorrect data is discarded before the data is delivered further to the Göta Älv water quality association (GÄVVF). Therefore, any remaining outliers may be real but different.

The data on river flow were obtained at the hydropower stations (located at Vargön, Trollhättan, and Lilla Edet) and at one location in the Nordre Älv. The flow in the continuation of the Göta Älv downstream the bifurcation is calculated as the difference between the discharge at the hydropower station in Lilla Edet and the river flow in Nordre Älv. Water levels are recorded at the hydropower stations. As an example, Fig. 3 shows the precipitation, flow, and turbidity for two different years (2002/2003 and 2006/2007) in the time series studied. The data are plotted with respect to the annual cycle of the hydrological processes, here chosen to be 1 August to 31 July (a hydrologic year). In 2006/2007 the fall was a period with intense, long-duration rainfalls over a large part of W/SW Sweden, which is reflected in the unusually high discharge during this period. The year 2002/2003 is more normal in terms of flow and turbidity variations.
Table 1. Min, max, standard deviation and variance of minute mean data for two of the days shown in Fig. 4, and for daily mean data for the whole period shown in Fig. 4.

\begin{tabular}{lcccr}
\hline & Min & Max & Stdv & Variance \\
\hline $\begin{array}{l}\text { 20 Oct 2006 (normal turbidity), } \\
\text { minute mean }\end{array}$ & 2.9 & 10.1 & 0.95 & 0.89 \\
$\begin{array}{l}\text { 3 Nov 2006 (high turbidity), } \\
\text { minute mean }\end{array}$ & 17.4 & 45.0 & 1.83 & 3.35 \\
$\begin{array}{l}\text { 20 Oct-9 Nov 2006, } \\
\text { daily mean }\end{array}$ & 3.97 & 20.8 & 5.4 & 29.17 \\
\hline
\end{tabular}

The precipitation data were gathered from the Swedish Meteorological and Hydrological Institute (SMHI) and data from Göteborg area (gauging station GöteborgA) and the community of Lilla Edet (gauging station Garn) were used in the present study. Station GöteborgA is located about $4 \mathrm{~km}$ SSW of the turbidity gauging station Lärjeholm (Fig. 1). The basic precipitation data employed, as well as the other data series, encompassed daily averages between 2002 and 2007 with respect to the Lärjeholm gauging station, and between 2004 and 2006 with respect to the Garn gauging station (due to missing data). The precipitation data does not differentiate between rain or snow. The annual mean precipitation for Göteborg (2001-2007) was $922 \mathrm{~mm}$. A longer period with frontal rainfall normally occurs from November to January, with shorter periods of convective rainfall in July and August (see Fig. 3).

\subsection{Data analysis}

The data analysis strategy involved a stepwise statistical approach focusing on daily, monthly, and yearly data on turbidity, flow, water level, and precipitation with the purpose to identify, describe, and explain the turbidity variations in time and space. The current turbidity analysis does not include short-term variation, on a timescale of less than a day. This includes, for example, turbidity variations induced by vessel traffic (see Althage and Larson, 2010). It is expected that such signals are negligible or make a similar contribution on a daily basis because of their short peak duration, and will not have any significant impact on the variation in the daily mean values. See Fig. 4 and Table 1 for an example. From this example, it is seen that the standard deviation for the minute mean is less than that for the daily mean, strengthening the assumption.

Linear correlation and regression analyses were used for different data sets derived from the recorded mean daily values. Also, nonparametric tests (for test method assurance) and factorial and main effect ANOVA were performed. For the linear correlation, the Pearson $r$ was used with a significance level $(p)$ of 0.05 . Since the sample data were daily mean values covering several years, the sample distribution was assumed to follow a normal distribution, which was 

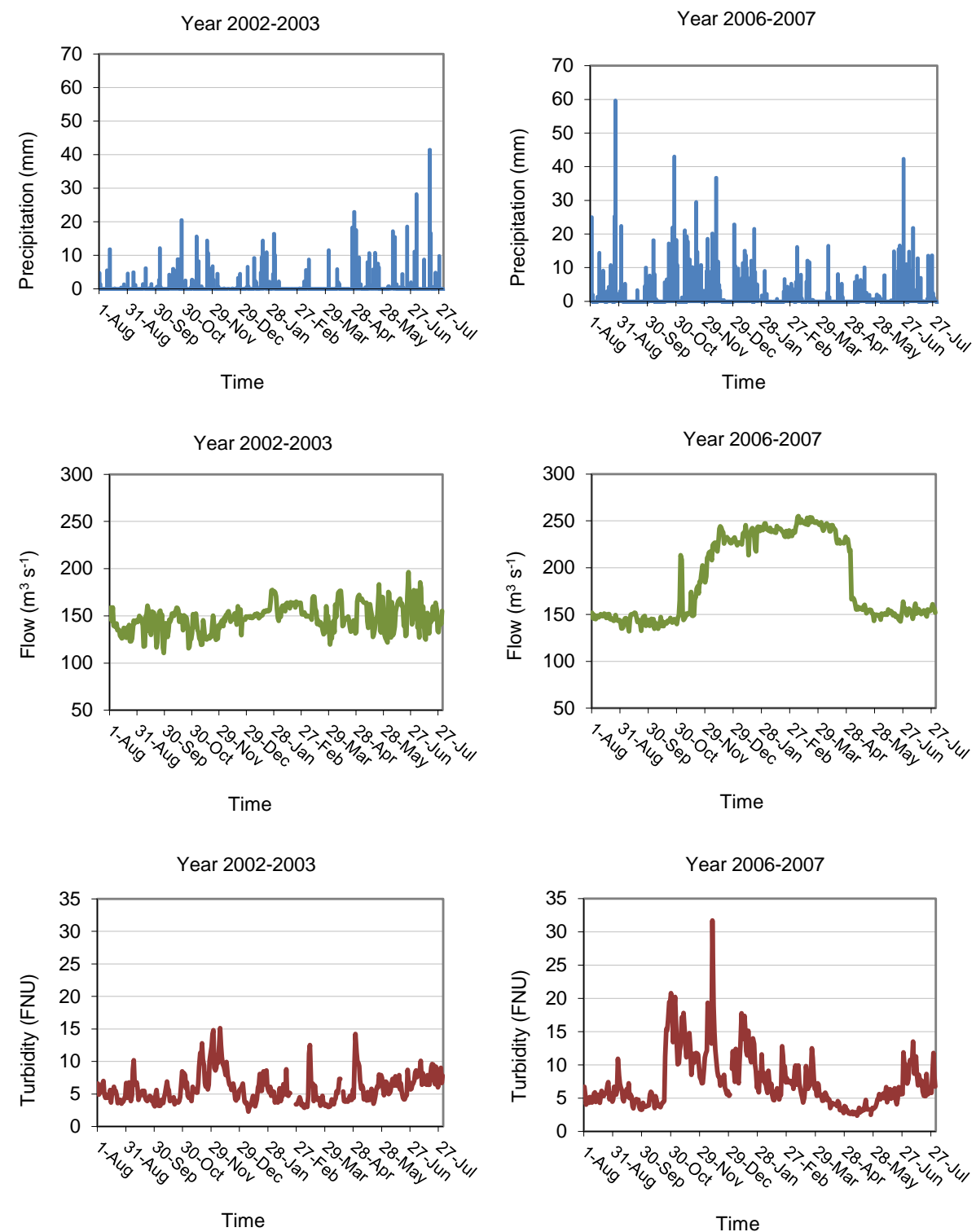

Fig. 3. A time series of precipitation, flow and turbidity in the southern branch of river Göta Älv for the hydrologic years of $2002 / 2003$ and 2006/2007.

confirmed through statistical tests. Nonparametric correlation did not yield any major differences in the result, lending confidence to the use of the linear correlation model. Therefore, only the results of the latter analysis will be presented here. The statistical software Statistica (Statsoft; Version 9) was primarily used for the different types of analyses discussed.

Missing data were treated by casewise deletion. The time period and time resolution employed in the analysis influenced the results; thus, some years showed better correlations between the variables than other years (for example, 2006/2007). Monthly mean values smooth out variations and increase the correlation compared to daily mean values.
Previous work has shown that the suspended matter in the Göta Älv mostly contains clay particles and that there seem to be a linear relationship between turbidity and suspended sediment concentration $\left(r^{2}=0.88\right)$ (Göransson et al., 2011), in agreement with other studies (see for example Lenhart et al., 2010; Pavanelli and Bigi, 2005a,b; Pavanelli and Pagliarani, 2002; Zonta et al., 2005). However, the correlation was only based on 12 samples of which some were affected by ship passages. Loss on ignition indicated a content of about $2-20 \%$ organic matter; the lower value is most likely an effect of ship passage during sampling.

With regard to the variables studied, $P(\mathrm{~mm})$ refers to precipitation, $Q\left(\mathrm{~m}^{3} \mathrm{~s}^{-1}\right)$ to flow, WL (m) to water level (refers to a deviation from a reference level which corresponds to the 
Minute mean

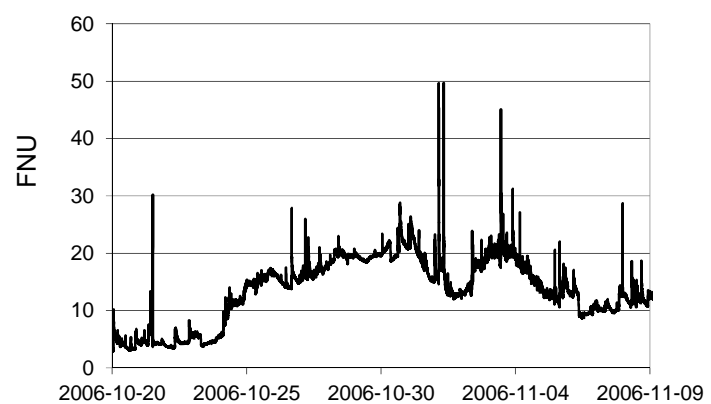

Daily mean

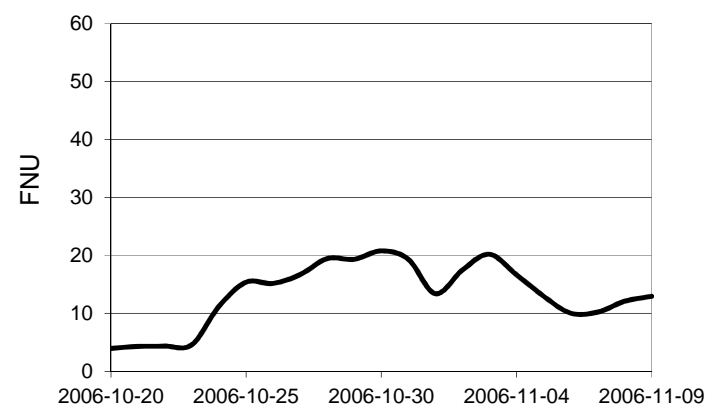

Fig. 4. An example of observed turbidity illustrated with minute mean data (left panel) and daily means data (right panel) for the arbitrary chosen time 29 October-9 November 2006. Ship traffic causes the strong peaks that are seen in the minute mean data (left panel).

Table 2. Mean, standard deviation, and correlation for annual data at Lärjeholm (2002-2007), and for the variables turbidity $(T)$, precipitation $(P)$, flow $(Q)$ and water level (WL). Correlation in bold is significant at $p<0.05$.

\begin{tabular}{lllclc}
\hline & Mean & $\begin{array}{l}\text { Std. } \\
\text { Dev. }\end{array}$ & $\begin{array}{c}P \text { GöteborgA } \\
{[\mathrm{mm}]}\end{array}$ & $\begin{array}{l}Q \text { Göta } \\
\text { River } \\
{\left[\mathrm{m}^{3} \mathrm{~s}^{-1}\right]}\end{array}$ & $\begin{array}{c}\text { WL } \\
\text { Lilla } \\
\text { Edet } \\
{[\mathrm{m}]}\end{array}$ \\
\hline$T$ Lärjeholm [FNU] & 6.6 & 0.7 & 0.59 & 0.7 & 0.71 \\
$P$ GöteborgA $[\mathrm{mm}]$ & 2.6 & 0.45 & & 0.44 & 0.62 \\
$Q$ Göta River [m $\left.{ }^{3} \mathrm{~s}^{-1}\right]$ & 158 & 11.7 & & & $\mathbf{0 . 9 6}$ \\
WL Lilla Edet $[\mathrm{m}]$ & 1.5 & 0.1 & & & \\
\hline
\end{tabular}

mean sea level), and $T$ (FNU) to turbidity. In the following, a brief summary of the results obtained during each step of the analysis outlined above are presented. Additional interpretations and comments to the analysis results are provided in the subsequent discussion section.

\section{Results}

\subsection{Data time series properties}

The annual averages from 2002 to 2007 were first calculated from the data using daily mean values. These averages were then analysed with regard to the relationship between precipitation, discharge, water level, and turbidity. Table 2 summarises the descriptive statistics. On an annual basis, the turbidity displays a positive correlation with $Q, P$, and $\mathrm{WL}$ (about $r=0.7$ ), although the statistical significance is low due to the limited number of years available. In spite of the river being regulated, correlation is expected between $T$ and $Q$, as a larger $Q$ would yield more transport, both in the river and from the catchment, influencing $T$ on an annual timescale. A strong correlation between $Q$ and WL is observed $(r=0.96)$, simply because a higher WL is typically associated with a larger $Q$.
Table 3. Mean, standard deviation, and correlation for daily mean data at Lärjeholm (2002-2007), and for the variables turbidity $(T)$, precipitation $(P)$, flow $(Q)$ and water level (WL). Correlation in bold is significant at $p<0.05$.

\begin{tabular}{lcrcrc}
\hline & Mean & $\begin{array}{r}\text { Std. } \\
\text { Dev. }\end{array}$ & $\begin{array}{c}P \text { GöteborgA } \\
{[\mathrm{mm}]}\end{array}$ & $\begin{array}{r}Q \text { Göta } \\
\text { River } \\
{\left[\mathrm{m}^{3} \mathrm{~s}^{-1}\right]}\end{array}$ & $\begin{array}{c}\text { WL } \\
\text { Lilla } \\
\text { Edet } \\
{[\mathrm{m}]}\end{array}$ \\
\hline$T$ Lärjeholm [FNU] & 6.6 & 3.5 & $\mathbf{0 . 1 2}$ & $\mathbf{0 . 1 7}$ & $\mathbf{0 . 2 3}$ \\
$P$ GöteborgA [mm] & 2.6 & 5.3 & & -0.01 & $\mathbf{0 . 0 8}$ \\
$Q$ Göta River [m $\left.{ }^{3} \mathrm{~s}^{-1}\right]$ & 158 & 28.4 & & & $\mathbf{0 . 8 0}$ \\
WL Lilla Edet $[\mathrm{m}]$ & 1.5 & 0.4 & & & \\
\hline
\end{tabular}

Daily mean values for the entire time series (station Lärjeholm; summary statistics given in Table 3) showed surprisingly weak, but significant, correlations for $T$ versus $P$ $(r=0.12)$ and $T$ versus $Q(r=0.18)$. An analysis of daily mean values was also carried out for the shorter period 2004 2006 for both gauging stations Lärjeholm and Garn. Limiting the analysis to three years (2004-2006) when the precipitation and discharge were unusually high emphasizes the dependency, yielding a stronger correlation between $T$ and $Q$ (Lärjeholm: $r=0.27$; Garn: $r=0.26$ ).

The time-series analyses of several years do not correlate turbidity with precipitation and discharge at a daily timescale well. This indicates that the relationship between the variables is not as straight forward as for non-regulated or less regulated rivers.

\subsection{Temporal dependences}

The statistical analysis was repeated for a number of limited time series, or single events, to understand better the variation in turbidity with runoff and flow. Eight events were chosen, five from Lärjeholm and three from Garn, each representing a particular type of precipitation or flow pattern, where either the flow, precipitation, or both, had one or several peaks. However, low correlation values were again obtained between $P, Q$, and $T$ for the events studied, except in 


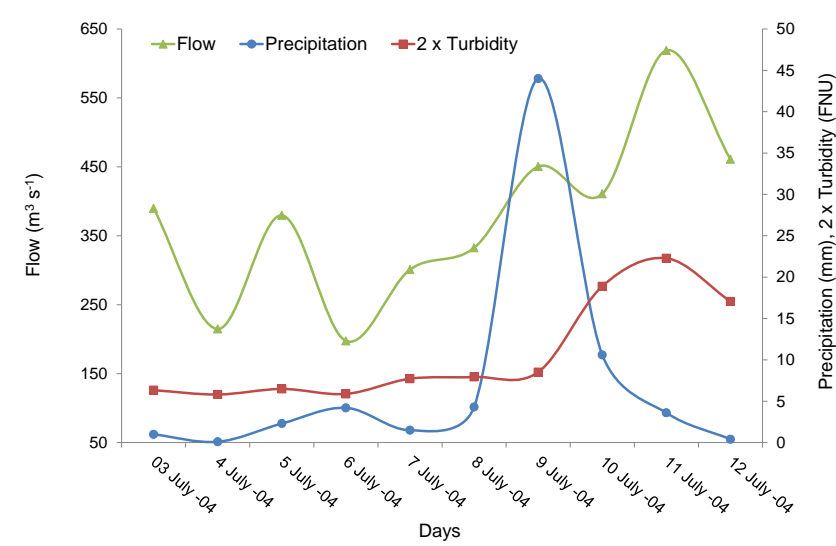

Fig. 5. A time series of daily mean values for precipitation, flow, and turbidity at Garn from 3 to 12 July 2004. Note that turbidity has been multiplied with 2 for a better resolution.

a few cases. Figure 5 illustrates one event where a marked and significant correlation was obtained between $T$ and $Q$ $(r=0.78)$. The figure also indicates a clear relationship between $P$ and $Q$, although the response in $Q$ is delayed, most likely because of the runoff process. With reference to the peaks, this delay is about three days, which is suggestive of a rainfall event at the catchment scale. The rapid variation at the daily timescale for $Q$, before the rainfall event, demonstrates the effect of short-term regulation in the hydropower plants; a factor that obscures a clear relationship between the studied variables. In another event, recorded at Lärjeholm on 3 May through the 22 May 2002, the peaks in $Q$ and $T$ clearly follow the peak in $P$ with some time delay indicating a strong relationship. However, stronger correlations between $P, Q$, and $T$ were expected for the event-based analyses, and the lack of such correlations indicates that the system is more complex with peaks in $P$ and $Q$ is not leading to an immediate response in $T$.

Also more extreme events were investigated to see whether the correlation between turbidity and the other variables studied would increase under such conditions. Four types of events (cases) recorded at the station Garn (2004-2006) were selected, since the relationship between the variables seemed to be somewhat stronger at this station than at Lärjeholm, namely (1) high turbidity events ( $T>20 \mathrm{FNU})$, (2) high discharge events (20 highest discharge events), (3) heavy rainfall events in summer (10 highest rainfall events), and (4) heavy rainfall events in winter (10 highest rainfall events).

The results indicated that extreme events do not have a clear impact on the variation in turbidity. For example in Case 1, the selection of high turbidity events only marginally improved the correlation between $T, Q$, and $P$. Overall, for the various cases investigated, the only markedly improved correlation found was between $T$ and WL for the highest discharge events $(r=0.60)$.

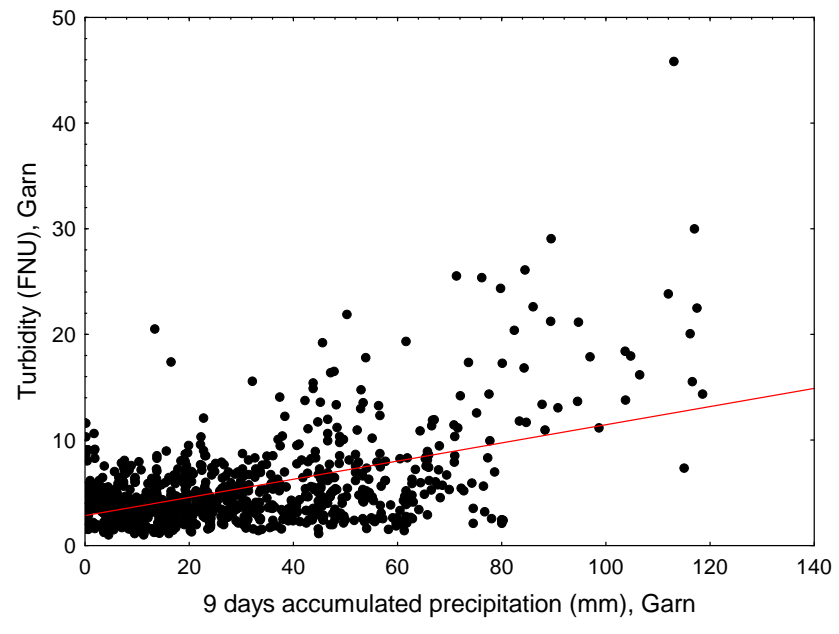

Fig. 6. Correlation between turbidity and 9 days of accumulated rain at station Garn, 2004-2006 ( $r=0.52, p<0.05)$.

As shown in Fig. 5, there is typically a delay in the flow and turbidity response to precipitation. In addition, a certain amount of rainfall is needed in order to yield sufficient runoff to produce a sediment transport resulting in increased turbidity in the river water. The lag time was investigated by shifting the data on $T$ and $Q$ up to 11 days with respect to $P$. Also, $T$ was compared to accumulated data on $P$ up to 13 days (days with zero rainfall included). Delaying $T$ with respect to $P$ at various time steps in the correlation analysis for daily values marginally improved the coefficient values. However, a delay in the analysis of $T$ versus $Q$ slightly improved the correlation, although it is still rather low $(r=0.24)$.

Accumulated $P$ versus $T$ increased the correlation with the length of the accumulation period. This increase continued up to a period of about 11 days for Lärjeholm $(r=0.48)$ and about 9 days for Garn ( $r=0.52$, Fig. 6). These results indicate that a certain amount of rainfall is needed before the occurrence of surface runoff and erosion. Thus, long periods of rainfall are necessary in order to influence the turbidity in the river. The length of this period may depend on the soil conditions and the general characteristics of the catchment and the river, but the time delay obtained corresponding to the maximum correlation values indicates a typical length.

From these results it is reasonable to believe that catchment size is a significant factor. Probably, on some occasions the catchment characteristics and size of Lake Vänern do govern turbidity variations in the river. According to the studies by Duvert et al. (2011), the percentage of time needed to carry $50 \%$ of the annual suspended sediment flux increases with increasing catchment size. For the Göta Älv, this means that the large catchment of Lake Vänern and the lake itself evens out precipitation and flow peaks, and thereby attenuates the correlation between the variables $P$ and $Q$ with $T$.

A seasonal variation in turbidity is expected, which is also seen in Fig. 7. It was found that a slightly stronger correlation 


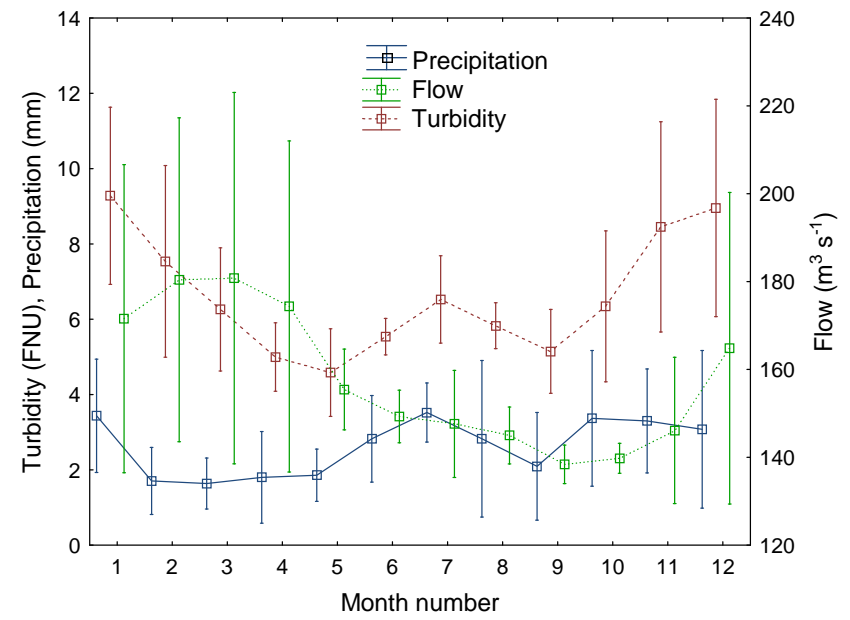

Fig. 7. Monthly mean for precipitation at station GöteborgA, flow in the river Göta Älv, the southern branch, and turbidity at station Lärjeholm (2002-2007).

between $P$ and $T$ occurred during winter (DecemberMarch, $r=0.18$ ) than during summer (June-August, $r=0.06$, $p \gg 0.05$ ), which may be explained by a general higher discharge and by less vegetation on the surface during the winter months. Vegetation stabilises the soil surface, preventing erosion and sediment transport. Decreasing the time resolution to monthly mean values improved the overall correlation $(r=0.55$ at $p=0.07)$, but only July and November showed marked correlation for $T$ versus $P(r=0.89$ and $r=0.87$, respectively).

The monthly mean values reveal a pattern with clearly higher variability in turbidity and discharge (water level) during the winter season (wet period), which is not as evident for the precipitation. The high variability in discharge during the winter is most likely an effect of the fluctuating energy demand, which induces short-term regulation of the river flow on a timescale of days. The high variability in turbidity during winter is partly due to the discharge, but variations in the vegetation cover and its effect on runoff and erosion may also be important.

The temporal persistence in the daily and monthly turbidity data was investigated using autocorrelation analysis (Fig. 8). Analysis based on daily data revealed strong autocorrelation for the turbidity over a timescale of weeks. Thus, events affecting the turbidity should have this typical duration, which is in agreement with the analysis for accumulated data discussed previously. Autocorrelation of monthly data on turbidity showed a typical sinusoidal shape with a period of one year that is characteristic for seasonal variations. Most of the factors influencing turbidity, such as precipitation, flow, vegetation, and temperature, have seasonal cycles producing a variation in the turbidity with a period of one year.
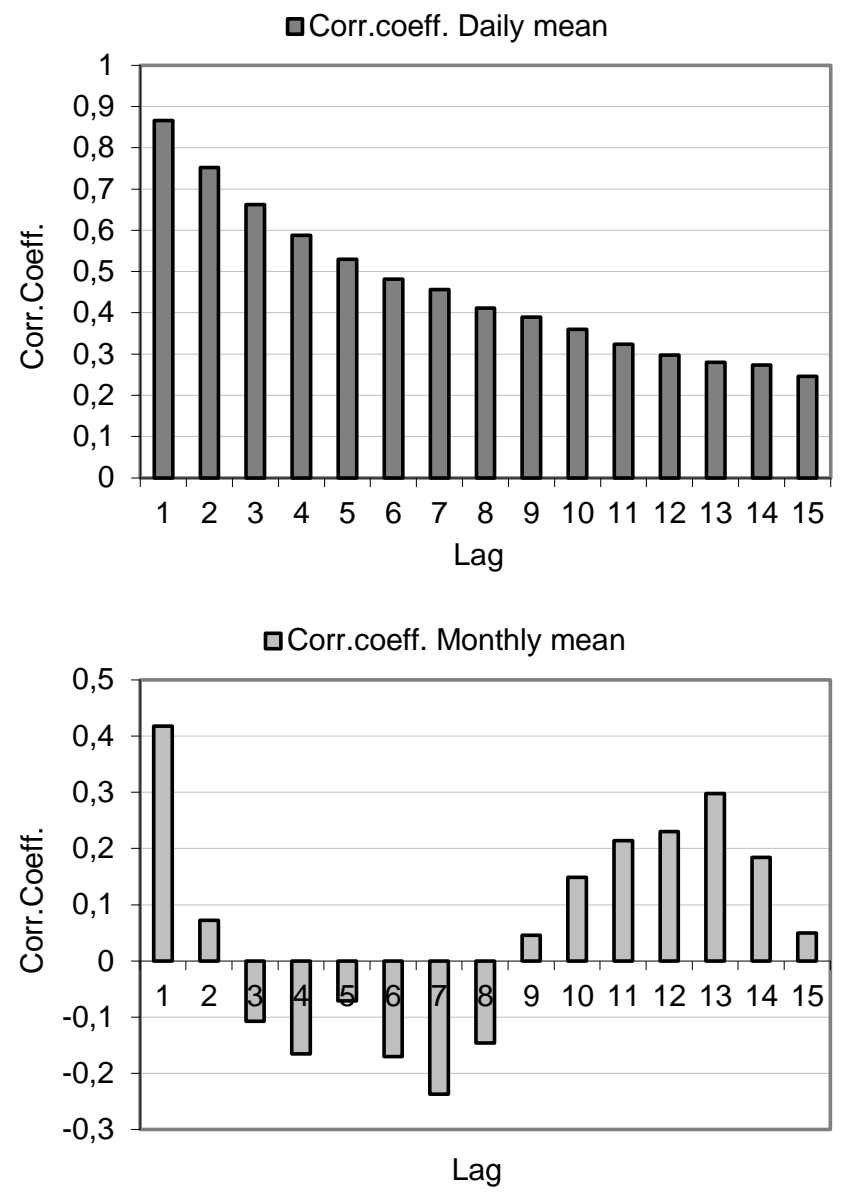

Fig. 8. Autocorrelation of turbidity at a daily (top diagram) and on a monthly (bottom diagram) basis, gauging station Lärjeholm (2002-2007).

\subsection{Spatial variations}

Spatial variability in flow and turbidity can partly be attributed to contributions from tributaries. Data from the main tributaries (Grönån, Gårdaån, and Slumpån; see Fig. 1) were compiled as monthly mean values. These data included only the years 2004 through 2006, since comparisons where made with both Garn and Lärjeholm. Turbidity at Garn exhibited a strong correlation with the discharge from the tributaries in contrast to the correlation with the discharge in the main river (Table 4). This is explained by the high correlation between $P$ and $Q$ in the tributaries, indicating natural conditions (no regulation) and limited detention storage. The correlations between the $T$ at Lärjeholm and $Q$ in the tributaries were lower; however, this station is located farther downstream from where the tributaries empty into the river.

Sediment is supplied from surface runoff, tributaries, and erosion of the river bed and bank along this stretch (assuming most of the sediment provided to the river is not deposited). Thus, an increase in turbidity is expected downstream from Lake Vänern toward the city of Göteborg. The 
Table 4. Comparison between the main river and three of the main tributaries with respect to turbidity $(T)$, flow $(Q)$, precipitation $(P)$ and water level (WL). The table shows data on mean and standard deviation, as well as correlation data for the variables $T, P$ and $Q$ (2004-2006). Correlation in 864 bold is significant at $p<0.05$.

\begin{tabular}{|c|c|c|c|c|c|c|c|c|c|c|c|}
\hline & Mean & $\begin{array}{l}\text { Std. } \\
\text { Dev. }\end{array}$ & $\begin{array}{c}T \\
\text { Lärjeholm } \\
{[\mathrm{FNU}]}\end{array}$ & $\begin{array}{c}Q \\
\text { Slumpån } \\
{\left[\mathrm{m}^{3} \mathrm{~s}^{-1}\right]}\end{array}$ & $\begin{array}{c}Q \\
\text { Lilla Edet } \\
{\left[\mathrm{m}^{3} \mathrm{~s}^{-1}\right]}\end{array}$ & $\begin{array}{c}Q \\
\text { Gårdaån } \\
{\left[\mathrm{m}^{3} \mathrm{~s}^{-1}\right]}\end{array}$ & $\begin{array}{c}Q \\
\text { Grönån } \\
{\left[\mathrm{m}^{3} \mathrm{~s}^{-1}\right]}\end{array}$ & $\begin{array}{c}Q \\
\text { Göta Älv } \\
{\left[\mathrm{m}^{3} \mathrm{~s}^{-1}\right]}\end{array}$ & $\begin{array}{r}P \\
\text { Garn } \\
{[\mathrm{mm}]}\end{array}$ & $\begin{array}{c}P \\
\text { GöteborgA } \\
{[\mathrm{mm}]}\end{array}$ & $\begin{array}{c}\text { WL } \\
\text { Lilla Edet } \\
{[\mathrm{m}]}\end{array}$ \\
\hline$T$ Garn [FNU] & 5.2 & 2.7 & 0.68 & 0.70 & 0.43 & 0.71 & 0.72 & 0.48 & $\mathbf{0 . 5 3}$ & 0.61 & 0.56 \\
\hline$Q$ Slumpån $\left[\mathrm{m}^{3} \mathrm{~s}^{-1}\right]$ & 5.7 & 4.8 & & & 0.55 & 0.97 & 0.96 & 0.59 & 0.45 & 0.44 & 0.65 \\
\hline$Q$ Lilla Edet $\left[\mathrm{m}^{3} \mathrm{~s}^{-1}\right]$ & 475 & 176 & & & & 0.54 & 0.55 & 0.92 & -0.07 & 0.04 & 0.92 \\
\hline$Q$ Gårdaån $\left[\mathrm{m}^{3} \mathrm{~s}^{-1}\right]$ & 0.9 & 0.72 & & & & & 0.99 & 0.61 & 0.51 & 0.51 & 0.69 \\
\hline$P$ Garn $[\mathrm{mm}]$ & 2.9 & 1.4 & & & & & & & & 0.89 & 0.15 \\
\hline$P$ GöteborgA $[\mathrm{mm}]$ & 2.7 & 1.5 & & & & & & & & & 0.25 \\
\hline WL Lilla Edet [m] & 1.4 & 0.3 & & & & & & & & & \\
\hline
\end{tabular}

Table 5. The table shows mean, standard deviation, and correlation for the variables turbidity $(T)$, flow $(Q)$ and precipitation $(P)$ along the river (2004-2007). Correlation in bold is significant at $p<0.05$.

\begin{tabular}{|c|c|c|c|c|c|c|c|c|c|c|}
\hline & Mean & $\begin{array}{l}\text { Std. } \\
\text { Dev. }\end{array}$ & $\begin{array}{c}T \\
\text { Lärjeholm } \\
{[\text { FNU] }}\end{array}$ & $\begin{array}{c}Q \\
\text { Vargön } \\
{\left[\mathrm{m}^{3} \mathrm{~s}^{-1}\right]}\end{array}$ & $\begin{array}{c}Q \\
\text { Trollhättan } \\
{\left[\mathrm{m}^{3} \mathrm{~s}^{-1}\right]}\end{array}$ & $\begin{array}{c}Q \\
\text { Lilla Edet } \\
{\left[\mathrm{m}^{3} \mathrm{~s}^{-1}\right]}\end{array}$ & $\begin{array}{c}Q \\
\text { Göta Älv } \\
{\left[\mathrm{m}^{3} \mathrm{~s}^{-1}\right]}\end{array}$ & $\begin{array}{r}P \\
\text { Vänersborg } \\
{[\mathrm{mm}]}\end{array}$ & $\begin{array}{r}P \\
\text { Garn } \\
{[\mathrm{mm}]}\end{array}$ & $\begin{array}{r}P \\
\text { GöteborgA } \\
{[\mathrm{mm}]}\end{array}$ \\
\hline$T$ Garn [FNU] & 5.8 & 4.2 & 0.69 & 0.22 & 0.22 & 0.27 & 0.31 & 0.12 & 0.16 & 0.14 \\
\hline$T$ Lärjeholm [FNU] & 7 & 3.5 & & 0.13 & 0.12 & 0.16 & 0.16 & 0.06 & 0.11 & 0.09 \\
\hline$Q$ Vargön $\left[\mathrm{m}^{3} \mathrm{~s}^{-1}\right]$ & 495 & 214 & & & 1.00 & 0.99 & 0.88 & -0.05 & -0.05 & -0.07 \\
\hline$Q$ Trollhättan $\left[\mathrm{m}^{3} \mathrm{~s}^{-1}\right]$ & 495 & 217 & & & & 0.99 & 0.87 & -0.05 & -0.05 & -0.07 \\
\hline$Q$ Lilla Edet $\left[\mathrm{m}^{3} \mathrm{~s}^{-1}\right]$ & 506 & 222 & & & & & 0.90 & -0.03 & -0.03 & -0.05 \\
\hline$Q$ Göta Älv $\left[\mathrm{m}^{3} \mathrm{~s}\right]$ & 160 & 30.2 & & & & & & -0.02 & -0.01 & -0.02 \\
\hline$P$ Vänersborg $[\mathrm{mm}]$ & 2.3 & 4.8 & & & & & & & 0.76 & 0.62 \\
\hline$P$ Garn $[\mathrm{mm}]$ & 3 & 6.1 & & & & & & & & 0.76 \\
\hline$P$ GöteborgA $[\mathrm{mm}]$ & 2.6 & 5.6 & & & & & & & & \\
\hline
\end{tabular}

interrelationships between gauging stations along the river have been analysed to quantify this increase. Daily data on measured discharges from the hydropower stations at Vargön (Vänersborg), Trollhättan, and Lilla Edet, the calculated discharge for the continuation of river Göta Älv, and precipitation data for Vänersborg, Garn, and Göteborg were used in the analysis, together with turbidity data from Lärjeholm and Garn (Table 5). Also, data from the other five turbidity stations were employed in the analysis. A substantial amount of data was missing from Station Gäddebäck and it was not included in the analysis.

As expected, the discharges at the three measuring stations for river flow are highly correlated, since more than $90 \%$ of the water in the studied stretch of the Göta Älv originates from Lake Vänern and the flow in the river is strongly regulated. The opening and closing of the discharge shield in the Nordre Älv, the contribution from tributaries, and effects from a varying sea water level explain the somewhat weaker correlation between $Q$ in the Göta Älv and $Q$ at the Vargön hydropower plant. The data also show an increase in turbidity moving south from Skräcklan (Lake Vänern) to Garn, a decrease from Garn to Södra Nol, and an increase from Surte to Lärjeholm. This spatial variation in turbidity indicates that the amount of material entering the river from Vänern has a large influence on the turbidity in the river. Thus, material from erosion of the river bed and banks and from surface runoff, directly or through the tributaries, only provides a minor contribution to the base level of turbidity. The river widens a few kilometres upstream from Södra Nol, and the lower mean turbidity recorded in Södra Nol may indicate some sedimentation in this area.

Correlation between the turbidity measured at the different stations yielded medium to high significance, with strong relationships for turbidity measured at adjacent stations. For example, the turbidity in Lärjeholm displays strong positive and significant correlation with the two closest (upstream) stations ( $r=0.72, r=0.86)$, indicating that turbidity in Lärjeholm is a function of the upstream turbidity. Södra Nol exhibited medium correlation to the upstream station Garn $(r=0.50)$. With the exception of Skräcklan, all stations demonstrate their lowest correlation with Garn. The river is quite narrow at Garn, implying higher velocities and possibly more sediment mobilization than for other river stretches, which may affect the turbidity. 
An important result is that the turbidity base level in the river is primarily a function of the inflow from Lake Vänern, whereas daily fluctuations reflect the contributions from sources along the river. The temporal variation in the turbidity of the lake varies at a slower timescale than the contribution to the turbidity from downstream sources along the river because of the size of the lake and its upstream catchment.

Next step was to analyse single series events; three types were chosen for the analysis of the spatial variation. The types were (1) a turbidity increase for several days at Skräcklan (from $\sim 4$ to $10 \mathrm{FNU}$ ) and a slight and not as evident increase in turbidity at the other stations, (2) a distinct turbidity increase for several days at Skräcklan (from $\sim 5$ to $10 \mathrm{FNU}$ ) and distinct and high peaks at the other stations (from $<10$ to 17-23 FNU), and (3) a distinct and high turbidity increase for several days at Skräcklan (from 3 to $20 \mathrm{FNU}$ ) and distinct increases at Garn and Lärjeholm (from $<5$ to 14-25 FNU) and Surte (from 2 to 8 FNU) (insufficient data for Södra Nol).

The higher the turbidity, the stronger the correlation proved to be between the turbidity measured at the stations. The two first types of events encompassed medium-low discharge in the Göta Älv together with low-medium rainfall; thus, the discharge in the river and/or precipitation could alone explain the large peaks in turbidity. The third type had low-medium discharge but medium-heavy rainfall. Figure 9 illustrates the temporal variation in turbidity at the stations along the river (except Gäddebäck) during the second type of event, which is typical when the input from Lake Vänern (Skräcklan) is not dominant. A distinct and high increase is displayed at all stations, except at Skräcklan that showed moderate increase, with a tendency for the mean turbidity level to increase in the downstream direction.

An explanation for the turbidity peaks, although mediumlow flows prevail, may be found by looking at the tributary flows, available on a weekly basis. The much higher tributary flows for the second and third type of event, in contrast to the main river flow, is a possible explanation for the higher turbidity peaks, as well as for the stronger and more significant correlation between turbidity at the gauging stations for these two types.

\subsection{Factorial and main effect ANOVA}

A factorial and main effect analysis (two-way ANOVA) was performed to evaluate two factors' influence on a third in order to study the effect of two independent categorical variables $(Q$ and $P$ ) on the dependent variable $(T)$. It is here assumed that flow $(Q)$ and precipitation $(P)$ are independent which, in reality, they are not. The reasoning behind this is that the flow in the studied river is governed by the energy demand and the regulation in Lake Vänern more than it is governed by precipitation. The independent variables $(Q$ and $P$ ) have thus been divided into three classes each instead

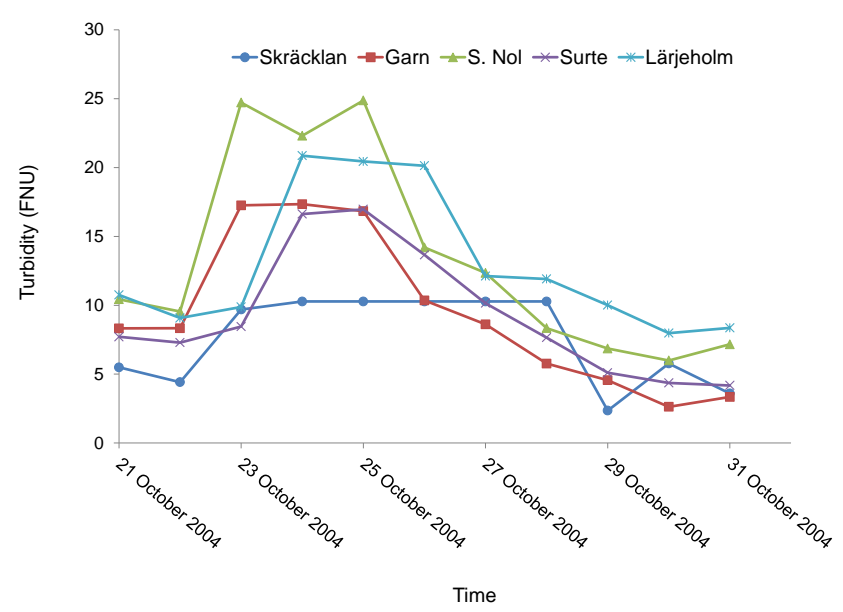

Fig. 9. Turbidity readings at five gauging stations, 21-31 October 2004 . The figure illustrates the temporal variation in turbidity along the river.

of using real values: flow data with river flow between 98 $150 \mathrm{~m}^{3} \mathrm{~s}^{-1}$ is given the flow class number 1 , flow data with river flow $151-200 \mathrm{~m}^{3} \mathrm{~s}^{-1}$ is given the number 2 , and flow data with river flow between $201-258 \mathrm{~m}^{3} \mathrm{~s}^{-1}$ is given the number 3 . The same has also been done for precipitation: zero precipitation is given the precipitation class number 1 , $0.1-20 \mathrm{~mm}$ is given the number 2 and $20.1-60 \mathrm{~mm}$ is given the number 3. The data on $Q$ and $P$ is then organised in a table were the flow classes and precipitation classes are combined in various ways with the resulting $T$ (the dependent variable).

Although the scoring could have been done differently, we believe the results, see Fig. 10, prove the overall indications laid out in the points below.

The main effect ANOVA analysis clearly shows is that both discharge and precipitation influence the turbidity. The chosen discharge classes generate almost equally sized $95 \%$ confidence level for turbidity, whereas the chosen precipitation classes generate larger $95 \%$ confidence intervals with higher classes. This is explained by the fact that the scored flow classes represent almost equal interval steps, which is not the case for precipitation. It could also be caused by the small sample size for the highest scored precipitation class. The results from the factorial and main effect ANOVA analysis differ somewhat between Lärjeholm and Garn, but overall they indicate the following:

- discharge in the main river has little impact on turbidity during dry periods (situations with no rain scenario precipitation class 1 );

- discharge in the main river starts to influence turbidity during medium rainfall. High discharge has quite a large impact on turbidity during medium rainfall, whereas medium and low discharge only has a minor impact; 
- discharge has a great impact on turbidity during heavy rainfall. High discharge has a larger impact on turbidity during high rainfall;

- during low discharge, heavy rain has only a slight influence on turbidity;

- rain intensity influences turbidity during medium discharge; and

- rain intensity has large impact on turbidity during high discharge; the more intense rainfall the greater the impact.

These results illustrate the complexity in the interdependencies and relationships between the variables studied. Periods of heavy rainfall are more sensitive to discharge variations than dry periods with regard to influencing the turbidity level. Similarly, periods of high discharge are more sensitive to rainfall intensity in terms of influencing the turbidity, although the confidence intervals for heavy rainfall are quite large. Nevertheless, the combination of heavy rain and high discharge generates the highest turbidity, however with the highest variability in turbidity. In comparison a dry period with low discharge has the lowest turbidity with the least variation.

\section{Discussion}

The results showed that there is no simple and general relationship between $P, Q$, and $T$ for the river system. The basic reason for this is the complexity of the river system, where the sediment originates from multiple sources with release strongly varying in time and space. The river regulation (the discharge is regulated at three hydropower plants that further determines the river flow) and Lake Vänern acting as a huge detention storage obscures the dependencies between variables. Precipitation has mostly an indirect impact on the flow in the river through the runoff to the lake and the discharge from the tributaries. More than $90 \%$ (in some cases 95-98\%) of the river flow downstream from the lake originates from the water in the lake.

It is also true that turbidity is reflected by local conditions and may change regardless of flow conditions, however, as a larger part of the turbidity contains particulate matter (clay, silt), there should be some correlation with flow and precipitation because of the shear stresses that are created from river flow and surface runoff. Also, turbidity generally increases downstream from gauging station to station. If a large part of the turbidity measured in the river was a result of resuspension and erosion of the material in the main river (i.e. from river bed and river banks), a strong positive correlation would have been obtained between $Q$ and $T$. The analysis shows only a weak, although significant, correlation for most cases investigated. This indicates that the material supplied from the river bed and banks is a limited portion of the sediment transport in the river and that wash load probably dominates, implying that the net sediment budget (Fig. 2) probably needs revision.

Taking into consideration a time delay in the response of $T$ to $Q$, the analysis only marginally improved the correlation. Analyses of time delays between $T$ and $P$, or accumulated $P$, indicated that a certain amount of $P$ is needed for a response in $T$, and that the duration of $P$ has a larger impact on $T$ than its intensity. The local precipitation does not have any significant impact on the discharge in the main river, which is primarily governed by the precipitation at the catchment scale together with the regulation of the river. One would have expected that extremes or series of events, including high discharge, high precipitation, or high turbidity would improve the correlations. However, it was found that explaining turbidity variations using simple measures of $P$ and $Q$ only is difficult. If the highest discharge events observed are investigated, medium significant correlation between $T$ and WL is found, and between WL and $Q$, but no significant correlation between $T$ and $Q$. Thus, it indicates that neither $Q$ nor $P$ alone governs the variation in $T$. There seems to be somewhat stronger relationships between the variables during the winter season, but also a larger variability in general. One explanation for the larger variability in turbidity during winter can be the higher discharge variations combined with more variable vegetation cover of the land surfaces.

A clearer pattern emerges if $T$ is analysed with respect to the spatial variation along the river, where $T$ at a specific location in the river influences $T$ downstream. The larger the magnitude of the turbidity peaks is, the stronger the correlation between adjacent gauging stations. During the winter season, stronger correlations for $T$ are obtained between the gauging stations compared to the summer season. An important contribution to the differences in $T$ between the stations, besides the erosion from the river bed and banks, is the transport from the tributaries. Analysis of single events indicated that discharge variations in these tributaries have a significant impact on $T$ and how it varies in space and time. Furthermore, $T$ displays stronger correlations to the discharges in the tributaries than to the discharge in the main river. A good correlation is observed between $P$ and the tributary $Q$. Thus, $Q$ in the small streams responds directly to rainfall, which generates runoff that brings sediment and organic matter from the surfaces to the tributaries and further out into the main river.

The amount of suspended sediment in Lake Vänern governs to a large degree the base level of the turbidity in the river, although the lake is not assumed to be the main delivery source. Contributions from surface runoff and tributaries along the river, as well as erosion of the river bed and banks, increase $T$ in the downstream direction. Since the changes in $T$ for Vänern is slow, the erosion processes in the river, on surfaces, and in the tributaries most likely determines the high levels and variability in $T$. 

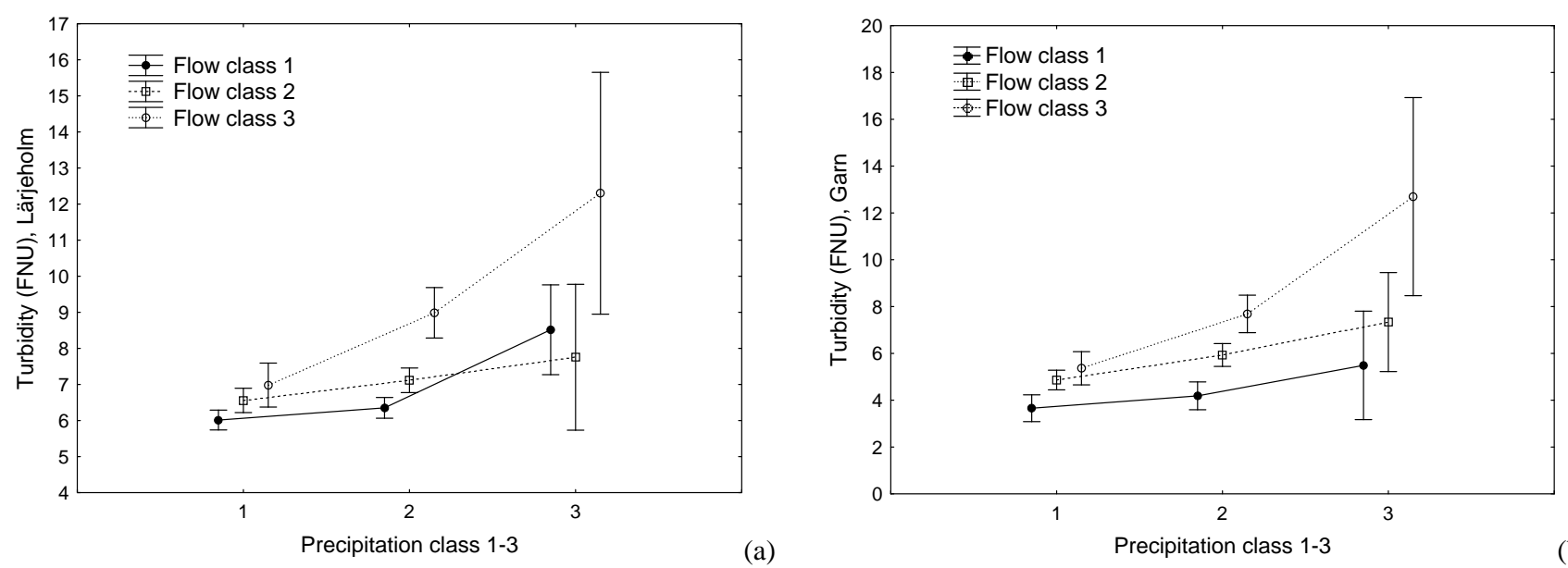

Fig. 10. Results of the factorial and main effect ANOVA analysis for the factors precipitation and discharge, and their influence on turbidity, measured at (a) Lärjeholm (2002-2007) and (b) at Garn (2004-2006). Data on precipitation and discharge were scored into tree classes: zero precipitation is precipitation class $1 ; 0.1-20 \mathrm{~mm}$ is precipitation class $2 ; 20.1-60 \mathrm{~mm}$ is precipitation class 3 , and $98-150 \mathrm{~m}^{3} \mathrm{~s}^{-1}$ is flow class $1 ; 151-200 \mathrm{~m}^{3} \mathrm{~s}^{-1}$ is flow class 2 ; and $201-258 \mathrm{~m}^{3} \mathrm{~s}^{-1}$ is flow class 3 . Vertical bars denote 0.95 confidence intervals, $p<0.05$.

The strong temporal persistence in $T$ (shown through the autocorrelation analysis) indicates a response timescale, for the system concerning the sediment transport, of about 10 days. Although the tributaries displayed the strongest correlation with $T$, there should still be influences from $Q$ and $P$. However, these relationships are complex and not easy to establish through the correlation analysis performed in this study. Another approach is factorial and main effect analysis of variance which was carried out with respect to the influence of the factors $Q$ and $P$ on the variable $T$. The results clearly indicated that during periods of heavy rainfall $T$ is more sensitive to flow variations than during dry periods. Similarly, $T$ during high flow periods seems to be more sensitive to rainfall intensity, although the confidence intervals for heavy rainfall are quite large. The combination of heavy rainfall and high discharge generate high $T$ but with the greatest variability, whereas the opposite applies for the combination of dry periods and low discharge. Occasions with high discharge and heavy rainfall cause flooding of adjacent floodplains and surface runoff from adjacent land surfaces, which brings particles, organic matter, nutrients (from cropland), fecal (from pasture land) and so on, into the river. In addition to such situations, sewage overflows are common. The study by Åström et al. (2007) clearly indicated a relationship between turbidity, precipitation, and e-coli, where e-coli was representing the release of bacteria from pasture land and sewage overflows.

Thus, in the studied river system, where the hydropower stations govern the flow, the river water mainly originates from a large lake. The local bed and bank erosion, local surface runoff, and tributary discharge governs turbidity, simple relationships between $Q, P$, and $T$ can only be found at specific occasions. The study by Tena et al. (2011) of the Ebro River showed that even though the river is regulated there is a direct linear relationship between suspended sediment concentration (as one part of turbidity) and discharge. It is hence possible that the weak relationship for river Göta Älv is not an effect of the regulation but of the buffering volume of Lake Vänern, making the responses very slow.

The study contributes to an increased understanding of the variation in turbidity and its causes especially in regulated river systems, which is of importance for the prediction of both short- and long-term impact on water quality from rainfall events. Suggestions on future studies are to analyse the content of the turbidity and the relationship to suspended sediment concentration further, and to investigate the sources of both turbidity and suspended sediments. Studies on hysteresis have not been done within this study but could also be a suggestion for future work.

\section{Conclusions}

Based on available data on turbidity, river flow and precipitation in a river with controlled river flow, it was necessary to find a methodology to interpret data in a structural way in order to find relationships between the studied variables. A stepwise statistical analysis is a useful approach to understand how processes in natural systems are affected by human activities. In a heavy regulated river with the main river water originating from a large lake (reservoir), it is probably not relevant to establish sediment rating curves for predicting suspended sediment transport, since the relationship between flow and suspended sediment concentration is not as straightforward as in natural or less disturbed river systems.

In the system under study, neither flow nor precipitation alone can explain turbidity levels and their variation. Correlation between discharge and turbidity in the river Göta Älv 
can only be found during specific circumstances, for example, heavy rainfall combined with high discharge that generates higher turbidity levels, or dry periods with low discharge that generates low turbidity levels. It is possible that these heavy rain-high flow events mainly cause the bed and bank erosion in Göta Älv, or overland erosion of temporarily flooded land areas.

The turbidity in the discharged water from Lake Vänern generates a base level in turbidity of the river water, whereas river bed and bank erosion, local surface runoff, and tributary flow (overland flow erosion and tributary riverbed/-bank erosion) govern the variability and high levels of turbidity in the river. Autocorrelation analysis indicated a temporal persistence for the turbidity of about 10 days. The contribution from the river bed and bank erosion is difficult to distinguish in the turbidity data.

The observed seasonal variation in turbidity is probably an effect of changes in the vegetation coverage and properties, and temperature, influencing the concentration of suspended matter, colloids, and organisms.

A significant dependence between adjacent gauging stations for the turbidity was observed, especially during the winter season, most likely due to less vegetation and more decomposed organic matter in the runoff. Large turbidity peaks yielded strong correlation between the gauging stations.

Acknowledgements. The authors would like to especially thank Åsa Henriksson and former employee Bengt Dahlberg at Göteborg Vatten (the Gothenburg water management), who provided us with the turbidity data and associated information, and the hydropower company Vattenfall for the provision of flow and water level data. Furthermore, we would like to thank Henrik Rydberg, Göteborg Vatten, Lackarebäck Laboratory, and Monica Dahlberg, GÄVVF (the Göta Älv water quality association), for supplying additional data and valuable information, and Åke Johansson (retired from the Swedish Geotechnical Institute) and Carina Hultén (Swedish Geotechnical Institute) for their valuable comments and information. We would like to acknowledge SGI and Formas (GG, ML; grant No. 2007-786) for funding the project. Finally, the comments from two reviewers are greatly appreciated and significantly improved the paper.

Edited by: A. D. Reeves

\section{References}

Alexandrov, Y., Laronne, J. B., and Reid, I.: Intra-event and interseasonal behaviour of suspended sediment in flash floods of the semi-arid northern Negev, Israel, Geomorphology, 85, 85-97, 2007.

Althage, J. and Larson, M.: Ship-induced waves and sediment transport in Göta river, Sweden, Lund University, Lund, Sweden, 2010 .
Antonelli, C., Eyrolle, F., Rolland, B., Provansal, M., and Sabatier, F.: Suspended sediment and 137Cs fluxes during the exceptional December 2003 flood in the Rhone River, southeast France, Geomorphology, 95, 350-360, 2008.

Åström, J., Pettersson, T. J. R., and Stenström, T. A.: Identification and management of microbial contaminations in a surface drinking water source, J. Water Health, 5, 67-79, 2007.

Bhutiani, R. and Khanna, D.: Ecological study of river Suswa: modeling DO and BOD, Environ. Monitor. Assess., 125, 183-195, 2007.

Chanson, H., Takeuchi, M., and Trevethan, M.: Using turbidity and acoustic backscatter intensity as surrogate measures of suspended sediment concentration in a small subtropical estuary, J. Environ. Manage., 88, 1406-1416, 2008.

Duvert, C., Gratiot, N., Némery, J., Burgos, A., and Navratil, O.: Sub-daily variability of suspended sediment fluxes in small mountainous catchments - implications for communitybased river monitoring, Hydrol. Earth Syst. Sci., 15, 703-713, doi:10.5194/hess-15-703-2011, 2011.

Gao, P., Pasternack, G. B., Bali, K. M., and Wallender, W. W.: Estimating Suspended Sediment Concentration Using Turbidity in an Irrigation-Dominated Southeastern California Watershed, J. Irrig. Drain. Eng., 134, 250-259, 2008.

Gauthier, V., Barbeau, B., Tremblay, G., Millette, R., and Bernier, A.-M.: Impact of raw water turbidity fluctuations on drinking water quality in a distribution system, J. Environ. Eng. Sci., 2, 281-291, 2003.

Göransson, G. I., Bendz, D., and Larson, P. M.: Combining landslide and contaminant risk: a preliminary assessment, J. Soil. Sediment., 9, 33-45, 2009.

Göransson, G. I., Persson, H., and Lundström, K.: Transport av suspenderat material i Göta älv (Transport of suspended sediments in the Göta river, Sweden), Swedish Geotechnical Institute, Linköping, 2011.

Håkanson, L.: Suspended particulate matter in lakes, rivers, and marine systems, edited by: U. U. Department of Earth Siences, Sweden, The Blackburn Press, Library of Congress Control Number: 2005922598, 2006.

Hamilton, J. L. and Luffman, I.: Precipitation, pathogens, and turbidity trends in the Little River, Tennessee, Phys. Geogr., 30, 236-248, 2009.

Hamilton, L. J., Shi, Z., and Zhang, S. Y.: Acoustic Backscatter Measurements of Estuarine Suspended Cohesive Sediment Concentration Profiles, J. Coast. Res., 14, 1213-1224, 1998.

Hawley, N.: A Comparison of Suspended Sediment Concentrations Measured by Acoustic and Optical Sensors, J. Great Lake. Res., 30, 301-309, 2004.

Hodgkins, R.: Controls on suspended-sediment transfer at a higharctic glacier, determined from statistical modelling, Earth Surf. Proc. Land., 24, 1-21, 1999.

Huey, M. G. and Meyer, L. M.: Turbidity as an Indicator of Water Quality in Diverse Watersheds of the Upper Pecos River Basin, Water, 2, 273-284, doi:10.3390/w2020273, 2010.

Iadanza, C. and Napolitano, F.: Sediment transport time series in the Tiber River, Phys. Chem. Earth A/B/C, 31, 1212-1227, 2006.

Kineke, G. C. and Sternberg, R. W.: Measurements of high concentration suspended sediments using the optical backscatterance sensor, Mar. Geol., 108, 253-258, 1992. 
Kvarnäs, H.: Morphometry and hydrology of the four large lakes of Sweden, Ambio, 30, 467-474, 2001.

Lawler, D. M., Petts, G. E., Foster, I. D. L., and Harper, S.: Turbidity dynamics during spring storm events in an urban headwater river system: The Upper Tame, West Midlands, UK, Sci. Total Environ., 360, 109-126, 2006.

Lenhart, C. F., Brooks, K. N., Heneley, D., and Magner, J. A.: Spatial and temporal variation in suspended sediment, organic matter, and turbidity in a Minnesota prairie river: implications for TMDLs, Environ. Monitor. Assess., 165, 435-447, 2010.

Lick, J. W.: Sediment and contaminant transport in surface waters, CRC Press Taylor \& Francis Group., 2009.

Lopez-Tarazon, J. A., Batalla, R. J., Vericat, D., and Francke, T.: Suspended sediment transport in a highly erodible catchment: The River Isabena (Southern Pyrenees), Geomorphology, 109, 210-221, 2009.

Maillard, P. and Pinheiro Santos, N. A.: A spatial-statistical approach for modeling the effect of non-point source pollution on different water quality parameters in the Velhas river watershed - Brazil, J. Environ. Manage., 86, 158-170, 2008.

Néstor, A. G., Lia, C. S., and Maria, C. C.: Planktonic and physicochemical dynamics of a markedly fluctuating backwater pond associated with a lowland river (Salado River, Buenos Aires, Argentina), Lake. Reserv. Res. Manage., 6, 133-142, 2001.

Ochiai, S. and Kashiwaya, K.: Measurement of suspended sediment for model experiments using general-purpose optical sensors, Catena, 83, 1-6, 2010.

Pavanelli, D. and Bigi, A.: A New Indirect Method to estimate Suspended Sediment Concentration in a River Monitoring Programme, Biosyst. Eng., 92, 513-520, 2005a.

Pavanelli, D. and Bigi, A.: Indirect Methods to Estimate Suspended Sediment Concentration: Reliability and Relationship of Turbidity and Settleable Solids, Biosyst. Eng., 90, 75-83, 2005 b.

Pavanelli, D. and Pagliarani, A.: SW - Soil and Water: Monitoring Water Flow, Turbidity and Suspended Sediment Load, from an Apennine Catchment Basin, Italy, Biosyst. Eng., 83, 463-468, 2002.

Pfannkuche, J. and Schmidt, A.: Determination of suspended particulate matter concentration from turbidity measurements: particle size effects and calibration procedures, Hydrol.1 Process., 17, 1951-1963, 2003.

Picouet, C., Hingray, B., and Olivry, J. C.: Empirical and conceptual modelling of the suspended sediment dynamics in a large tropical African river: the Upper Niger river basin, J. Hydrol., 250, 1939, 2001.

Rydell, B., Persson, H., Blied, L., Åström, S., and Gyllenram, J.: Fördjupningsstudie om erosion i vattendrag (In-depth study on erosion in rivers), Swedish Geotechnical Institute, Linköping, 2011.

Schmidt, K. H. and Morche, D.: Sediment output and effective discharge in two small high mountain catchments in the Bavarian Alps, Germany, Geomorphology, 80, 131-145, 2006.
Schoellhamer, D. H., Mumley, T. E., and Leatherbarrow, J. E.: Suspended sediment and sediment-associated contaminants in San Francisco Bay, Environmental Research, 105, 119-131, 2007.

Sundborg, Å. and Norrman, J.: Göta Älv Hydrologi och Morfologi med särskild hänsyn till Erosionsprocesserna, SGU - Geological Survey of Sweden, 1963.

Tena, A., Batalla, R. J., Vericat, D., and López-Tarazón, J. A.: Suspended sediment dynamics in a large regulated river over a 10year period (the lower Ebro, NE Iberian Peninsula), Geomorphology, 125, 73-84, 2011.

Thomas, B. R. and Lewis, J.: An evaluation of flow-stratified sampling for estimating suspended sediment loads, J. Hydrol., 170, 27-45, 1995.

Townsend-Small, A., McClain, M. E., Hall, B., Noguera, J. L., Llerena, C. A., and Brandes, J. A.: Suspended sediments and organic matter in mountain headwaters of the Amazon River: Results from a 1-year time series study in the central Peruvian Andes, Geochim. Cosmochim. Acta, 72, 732-740, 2008.

Vericat, D. and Batalla, R. J.: Sediment transport in a highly regulated fluvial system during two consecutive floods (lower Ebro River, NE Iberian Peninsula), Earth Surf. Proc. Land., 30, 385402, 2005.

Vernile, A., Nabi, A. Q., Bonadonna, L., Briancesco, R., and Massa, S.: Occurrence of Giardia and Cryptosporidium in Italian water supplies, Environ. Monitor. Assess., 152, 203-207, 2009.

Wang, X.-M., Hao, R., Huo, J., and Zhang, J.-F.: Modeling sediment transport in river networks, Physica A, 387, 6421-6430, doi:10.1016/j.physa.2008.07.027, 2008.

Wass, P. D., Marks, S. D., Finch, J. W., Leeks, G. J. L., and Ingram, J. K.: Monitoring and preliminary interpretation of in-river turbidity and remote sensed imagery for suspended sediment transport studies in the Humber catchment, Sci. Total Environ., 194 195, 263-283, 1997.

Williamson, T. N. and Crawford, C. G.: Estimation of SuspendedSediment Concentration from Total Suspended Solids and Turbidity Data for Kentucky, 1978-1995, J. Am. Water Resour. Ass., 47, 739-749, doi:10.1111/j.1752-1688.2011.00538.x, 2011.

Winston, W. E. and Criss, R. E.: Geochemical variations during flash flooding, Meramec River basin, May 2000, J. Hydrol., 265, 149-163, 2002.

Yang, G., Chen, Z., Yu, F., Wang, Z., and Zhao, Y.: Sediment rating parameters and their implications: Yangtze River, China, Geomorphology, 85, 166-175, 2007.

Zabaleta, A., Martinez, M., Uriarte, J. A., and Antiguedad, I.: Factors controlling suspended sediment yield during runoff events in small headwater catchments of the Basque Country, Catena, 71, 179-190, 2007.

Zonta, R., Collavini, F., and Zaggia, L.: The effect of floods on the transport of suspended sediments and contaminants: A case study from the estuary of the Dese River (Venice Lagoon, Italy), Environ. Int., 31, 948-959, 2005. 